\title{
HIGROTERMIČKE KARAKTERISTIKE ZGRADE U FUNKCIJI KLIMATSKIH PARAMETARA
}

\author{
Radmila Sinđić-Grebović ${ }^{1}$
}

УДК: $628.853: 624.04$

DOI:10.14415/konferencijaGFS 2015.009

Rezime: Transport vlage kroz elemente omotača može se analizirati primjenom različitih metoda, uz usvajanje različitih klimatskih parametara, što značajno utiče na pouzdanost rezultata. U radu se prikazuju rezultati proračuna međuslojne kondenzacije u funkciji usvojenih klimatskih podataka. Pri proračunu se koristi Glaserova metoda, koja je i pored aproksimativnih rješenja, još uvijek najšire prihvaćena. Utvrđeno je da su za validnost proračuna neophodne dobro definisane nacionalne odredbe o klimatskim parametarima.

Ključne riječi: difuzija vodene pare, međuslojna kondenzacija, klimatski parametri

\section{UVOD}

Prisustvo vlage utiče na energetske karakteristike i trajnost zgrada, kao i na uslove životnog komfora u njima. Ocjena higrotermičkih karakteristika zgrada obuhvata analizu transporta toplote i vlage, kao tečnosti ili kao vodene pare kroz elemente zgrade. Kretanje vlage kroz materijale može rezultirati lokalnim akumuliranjem vlage $u$ građevinskom elementu. Zadržavanje vlage u materijalima omotača zgrade može prouzrokovati dodatne probleme, kao što su: korozija, truljenje, oštećenja od mraza, vlaženje izolacije, tamnjenje unutrašnjih površina i pojava buđi na njima, kao i oštećenja opreme u zgradi.

Najčešća oštećenja koje se javljaju u zgradama potiču upravo zbog prisustva vlage. Takav stav potvrđuju i rezultati istraživanja Instituta za istraživanje zgrada u Hanoveru (Institut für Bauforschung e.V. Hannover), u kome se navodi da je od ispitanih 275 postojećih zgrada, kod 48\% oštećenje nastalo kao posljedica dejstva vlage, [1].

Vlaga se u elementima građevinskih konstrukcija javlja u obliku vode ili vodene pare. Transport vlage kroz materijale se odvija putem sljedećih mehanizama:

- U obliku difuzije vodene pare usljed gradijenta parcijalnog pritiska;

- Kretanjem vodene pare posredstvom kretanja vazduha;

- Kapilarnim upijanjem vode kroz pore u materijalu;

- Kretanjem tečne vode usljed gravitacione sile ili vazdušnog pritiska.

Zaštita materijala od upijanja tečne vode se može ostvariti prekidom otvora kapilarnih pora. Kretanje vlage kroz porozne materijale, u obliku vodene pare, teško može biti

\footnotetext{
${ }^{1}$ Radmila Sinđić-Grebović, Ph.D. assist.prof., University of Montenegro, Faculty of Civil Engineering Podgorica, Cetinjski put bb, Podgorica, Montenegro, tel: +382 20511 792, e - mail: radmilasg@gmail.com
} 
spriječeno. Pojava međuslojne kondenzacije nastaje u odgovarajućim higrotermičkim uslovima, pri kretanju vodene pare kroz materijal. Uslovi potrebni za pojavu kondenzacije zavise od temperature vazduha i pritiska vodene pare u slojevima materijala, u unutrašnjosti i izvan zgrade.

Kriterijumi za ocjenu elemenata zgrada u pogledu bezbjednosti od pojave međuslojne kondenzacije, prema EN ISO 13788, su:

a) Nema pojave kondenzacije na površinama unutar slojeva omotača, tokom bilo kojeg mjeseca u godini. U tom slučaju konstrukcija nije ugrožena međuslojnom kondenzacijom.

b) Kondenzacija se javlja na jednoj ili više međuslojnih površina, tokom određenih mjeseci u godini, ali postoje uslovi da ukupna vlaga akumulirana na taj način ispari tokom preostalog perioda godine, koji je bez kondenzacije. U tom slučaju se definiše mjesec u kome je akumulirana vlaga dostigla maksimalnu vrijednost $\mathrm{i}$ maksimalna količina akumulirane vlage. Ukoliko je vrijednost akumulirane vlage veća od $200 \mathrm{~g} / \mathrm{m}^{2}$, konstatuje se da postoji značajna opasnost od oštećenja elementa zgrade.

c) Kondenzacija se javlja u jednoj ili više međuslojnih površina, pri čemu nijesu stvoreni uslovi da akumulirana vlaga ispari tokom perioda godine u kojem ne dolazi do kondenzacije, [2].

\section{METODE ANALIZE HIGROTERMIČKIH KARAKTERISTIKA}

Metodologije proračuna osnovnih pokazatelja higrotermičkih karakteristika zgrade propisane su standardima EN 13788 i EN 15026. Postupci koje propisuju navedeni standardi su međusobno različiti. Prema EN 13788 predviđen je stacionarni model proračuna - Glaserov metod, dok je prema EN 15026 predviđen nestacionarni (dinamički) model.

Pretpostavke Glaserove metode su: proces difuzije vodene pare se odvija u stacionarnim uslovima, elementi zgrade ne propuštaju vazduh i kondenzovana vlaga se ne kreće. Karakteristike materijala su konstante, čak i u uslovima kondenzacije, do koje dolazi kad pritisak vodene pare dostigne pritisak zasićenja. Glaserov metod uzima u obzir samo kretanje vodene pare, dok zanemaruje efekte transporta tečnosti kroz elemente. Prema navedenoj metodi ne uzima se u obzir moguće skladištenje higroskopne vlage i vode $u$ porama materijala, [3-6].

Promjene vlažnosti na dnevnom nivou će dovesti do izmjene higrotermičkih uslova unutar omotača zgrade. Takođe je značajan uticaj vlage na karakteristike materijala, kao i kretanje vlage u sva tri pravca. Ugrađena vlaga zahtijeva duže vrijeme da ispari, i doprinosi izmjeni higrotermičkih karakteristika unutrašnjih elemenata. Za primjenu tačnijeg proračuna u odnosu na Glaserovu metodu, kakav je predviđen prema EN 15026, potrebno je obezbijediti dovoljno ulaznih podataka. EN 15026 propisuje nestacionarnu metodu. Zahtijevaju se klimatski podaci koji omogućavaju proračun međuslojne kondenzacije $\mathrm{i}$ isušenja u periodu $365 \times 24 \mathrm{~h}$. Ovakav proračun tretira transport vlage difuzijom i kapilarnim kretanjem, [1]. 
Међународна конференција

Савремена достигнућа у грађевинарству 24. април 2015. Суботица, СРБИЈА

\section{ULAZNI PARAMETRI ZA PRORAČUN}

Proračun prema EN ISO 13788 zahtijeva upotrebu ulaznih klimatskih podataka koji odgovaraju lokalnim uslovima. Podaci o klimatskim parametrima za proračun treba da budu utvrđeni na nacionalnom nivou. $U$ tom cilju preporučuje se formiranje baze klimatskih podataka. Klimatski podaci za proračun treba da budu formirani prema EN ISO 15927-1, na bazi podataka mjerenih na časovnom nivou. Parametri za proračun koji su usvojeni crnogorskim Pravilnikom o minimalnim zahtjevima energetske efikasnosti zgrada ne odgovaraju zahtjevima EN ISO 15927-1, već su utvrđeni prema karti JUS U.J5.600:1998, [7]. Pravilnik o minimalnim zahtjevima energetske efikasnosti zgrada ne propisuje unutrašnje klimatske parametre za proračun. Podaci korišćeni u ovoj analizi su usvojeni pomoću dijagrama na Slici 1 , u funkciji spoljašnje temperature $\theta_{\mathrm{e}}$.

Linije na dijagramu za određivanje relativne vlažnosti $\varphi_{i}$, označene sa A i B, odgovaraju slučajevima unutrašnjih prostora normalne i visoke naseljenosti, respektivno.

Tabela 1. Klimatski podaci propisani CG Pravilnikom [7]

\begin{tabular}{|c|c|c|c|c|c|c|c|c|c|c|c|c|c|}
\hline \multicolumn{2}{|r|}{ Zona } & Jan. & Feb. & Mart & Apr. & Maj & Jun & Jul & Avg. & Sep. & Okt. & Nov. & Dec. \\
\hline \multirow[b]{2}{*}{1} & $\theta_{\mathrm{e}}\left[{ }^{\circ} \mathrm{C}\right]$ & 5.5 & 6.5 & 10 & 13.8 & 19.8 & 24.5 & 26.7 & 26.5 & 20.7 & 16 & 10.8 & 6.5 \\
\hline & $\varphi_{e}[\%]$ & 72 & 68 & 65 & 66 & 63 & 60 & 52 & 52 & 62 & 68 & 75 & 74 \\
\hline \multirow{2}{*}{ II } & $\theta_{\mathrm{e}}\left[{ }^{\circ} \mathrm{C}\right]$ & 1.8 & 2.2 & 6.1 & 10.3 & 15.8 & 19.5 & 21.1 & 20.9 & 15.9 & 12.1 & 7.4 & 2.7 \\
\hline & $\varphi_{\mathrm{e}}[\%]$ & 72 & 70 & 67 & 67 & 67 & 67 & 57 & 59 & 66 & 71 & 75 & 73 \\
\hline & $\theta_{\mathrm{e}}\left[{ }^{\circ} \mathrm{C}\right]$ & -2.1 & -1.6 & 2.5 & 7.4 & 13 & 16.4 & 17.9 & 17.7 & 12.6 & 8.8 & 4 & -1.5 \\
\hline & $\varphi_{\mathrm{e}}[\%]$ & 83 & 78 & 73 & $\overline{70}$ & 71 & 74 & 72 & 72 & 76 & 78 & 81 & 85 \\
\hline
\end{tabular}

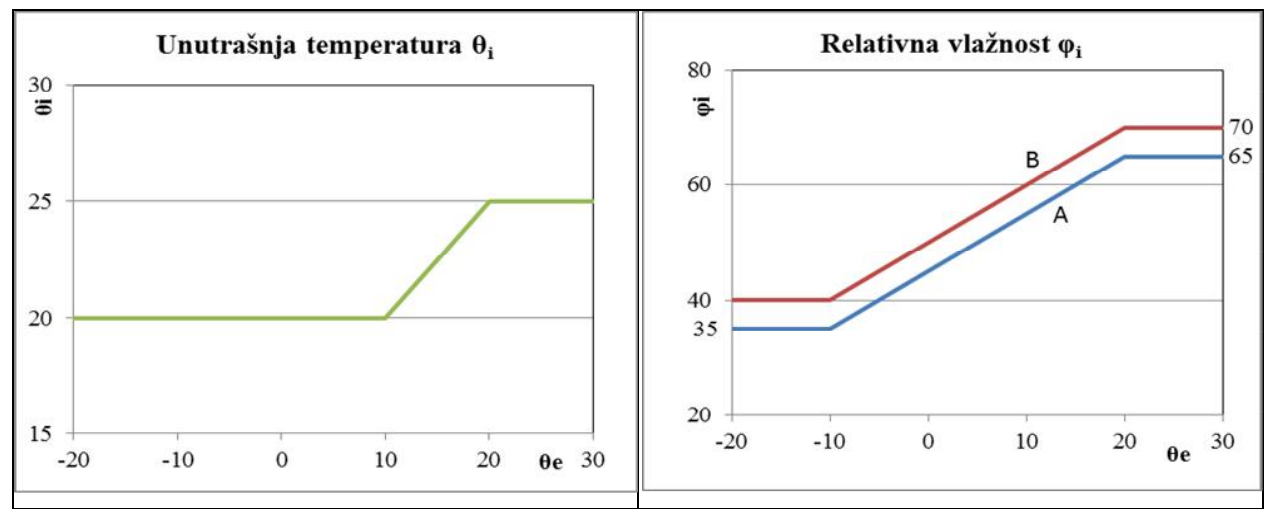

Slika 1. Definisanje parametara $\theta_{i} i \varphi_{i}$ u funkciji $\theta_{e}$, prema EN ISO 13788

\section{PRORAČUN MEĐUSLOJNE KONDENZACIJE}

Difuzija vodene pare kroz elemente omotača je prikazana na višeslojnim elementima koji imaju odgovarajući koeficijent U, propisan za dato klimatsko područje [7]. Za I i II zonu propisana vrijednost koeficijenta prolaza toplote $\mathrm{U}_{\max }=60 \mathrm{~W} /\left(\mathrm{m}^{2} \mathrm{~K}\right)$, dok je za III zonu propisana vrijednost koeficijenta $\mathrm{U}_{\max }=45 \mathrm{~W} /\left(\mathrm{m}^{2} \mathrm{~K}\right)$. 
International conference

Contemporary achievements in civil engineering 24. April 2015. Subotica, SERBIA

U predmetnoj analizi korišćena su dva različita tipa višeslojnog elementa sastavljena od slojeva iste debljine, ali od materijala različitih termoizolacionih karakteristika, tako da koeficijenti prolaza toplote dostignu približno granične vrijednosti za pojedine zone. Podaci su prikazani u Tabeli 2. Pri proračunu su za I i II klimatsku zonu korišćeni elementi oba tipa, $\mathrm{U}_{1}=0.425 \mathrm{~W} /\left(\mathrm{m}^{2} \mathrm{~K}\right)$ i $\mathrm{U}_{2}=0.58 \mathrm{~W} /\left(\mathrm{m}^{2} \mathrm{~K}\right)$. Za III zonu je korišćen samo element tipa $1, \mathrm{U}_{1}=0.425 \mathrm{~W} /\left(\mathrm{m}^{2} \mathrm{~K}\right)$, koji zadovoljava propisane uslove za tu zonu. Uračunati su i otpori površina $\mathrm{R}_{\mathrm{si}}=0.13 \mathrm{~W} /\left(\mathrm{m}^{2} \mathrm{~K}\right)$ i $\mathrm{R}_{\mathrm{se}}=0.04 \mathrm{~W} /\left(\mathrm{m}^{2} \mathrm{~K}\right)$.

Tabela 2. Karakteristike elemenata korišćenih u analizi

\begin{tabular}{|c|c|c|c|c|c|c|}
\hline & \multicolumn{3}{|c|}{ Element $1\left(\mathrm{U}_{1}=0.425 \mathrm{~W} / \mathrm{m}^{2} \mathrm{~K}\right)$} & \multicolumn{3}{|c|}{ Element $2\left(\mathrm{U}_{2}=0.58 \mathrm{~W} / \mathrm{m}^{2} \mathrm{~K}\right)$} \\
\hline Slojevi & $\begin{array}{c}\mathrm{d} \\
{[\mathrm{m}]}\end{array}$ & $\begin{array}{c}\mathrm{R} \\
{\left[\mathrm{m}^{2} \mathrm{~K} / \mathrm{W}\right]}\end{array}$ & $\begin{array}{c}\mathrm{s} \mathrm{d} \\
{[\mathrm{m}]}\end{array}$ & $\begin{array}{c}\mathrm{d} \\
{[\mathrm{m}]}\end{array}$ & $\begin{array}{c}\mathrm{R} \\
{\left[\mathrm{m}^{2} \mathrm{~K} / \mathrm{W}\right]}\end{array}$ & $\begin{array}{c}\mathrm{sd} \\
{[\mathrm{m}]}\end{array}$ \\
\hline Završni sloj & 0.025 & 0.100 & 0.2 & 0.025 & 0.025 & 0.25 \\
\hline Unutrašnji zid & 0.2 & 0.225 & 1.2 & 0.2 & 0.645 & 1.2 \\
\hline Termoizolacija & 0.05 & 1.515 & 0.05 & 0.05 & 0.555 & 0.15 \\
\hline Vazd. sloj & 0.05 & 0.18 & 0.05 & 0.05 & 0.18 & 0.05 \\
\hline Fasadni zid & 0.12 & 0.155 & 7.2 & 0.12 & 0.155 & 7.2 \\
\hline
\end{tabular}

\section{REZULTATI PRORAČUNA I ANALIZA}

Proračun parametara međuslojne kondenzacije prema EN ISO 13788 može poslužiti za uporedne ocjene elemenata konstrukcije i efekata intervencija na njima, ali ne i za proračun tačnih vrijednosti parametara kondenzacije i isušenja, jer se zasniva na bitno uprošćenim pretpostavkama, [2]. Prikazani rezultati proračuna na standardnim elementima omotača, koji zadovoljavaju osnovne minimalne energetske zahtjeve, pokazuju da proračun može rezultirati različitim ocjenama prihvatljivosti elemenata, $u$ zavisnosti od usvojenih klimatskih parametara. Rezultati proračuna su prikazani u Tabeli 3, pri čemu su klasifikovani prema klimatskim zonama. U okviru svake klimatske zone proračun je izvršen za klimatske parametre prikazane u Tabeli 1. Dodatni podaci o klimatskim parametrima, za koje je izvršen proračun, utvrđeni su prema zvanično objavljenim podacima Zavoda za hidrometereologiju i seizmologiju Crne Gore, http://www.meteo.co.me/. Za proračun su odabrane lokacije karakteristične za određenu zonu i to: Žabljak za III zonu, Nikšić i Crkvice za II zonu (Crkvice su mjesto sa najvećom količinom padavina) i Virpazar, mjesto na obali Skadarskog jezera, za I zonu. Podaci o relativnoj vlažnosti vazduha su usvojeni kako su dati Pravilnikom i prikazani u Tabeli 1. Relativna vlažnost vazduha je uvećana $10 \%$ za Crkvice i Virpazar, za drugi slučaj proračuna (označeno sa “+”). Rezultati proračuna su pokazali da se u klimatskoj zoni III javlja kondenzacija većeg stepena od one koja može biti isušena. Najveći stepen međuslojne kondenzacija se javlja za klimatske uslove Žabljaka, i to sa dvostruko više zaostale vlage na kraju perioda isušenja, nego što se dobija za klimatske uslove propisane za III zonu (kojoj inače Žabljak pripada). Takođe, za niži stepen naseljenosti A u III klimatskoj zoni, proračunom se dobija potpuno isušenje, što nije slučaj za klimatske uslove Žabljaka. Primijećeno je da se veća ukupna kondenzacija sa dužim 
Међународна конференција

Савремена достигнућа у грађевинарству 24. април 2015. Суботица, СРБИЈА

periodom isušenja dobija u slučaju manjeg koeficijenta prolaza toplote $U$, iako su ostali uslovi isti.

Tabela 3. Rezultati proračuna kondenzacije i isušenja

\begin{tabular}{|c|c|c|c|c|c|c|c|c|}
\hline \multirow{2}{*}{$\begin{array}{l}\text { Klimatski } \\
\text { podaci }\end{array}$} & \multirow{2}{*}{$\frac{\mathrm{U}}{\mathrm{W} /\left(\mathrm{m}^{2} \mathrm{~K}\right)}$} & \multirow{2}{*}{$\begin{array}{l}\text { Grupa } \\
\text { naselj. }\end{array}$} & \multicolumn{2}{|c|}{ Period kondenz. } & \multicolumn{2}{|c|}{ Period isušenja } & \multicolumn{2}{|c|}{$\begin{array}{c}\text { Količina } \\
\text { kondenzata } \mathrm{g} / \mathrm{m}^{2}\end{array}$} \\
\hline & & & Počet. & $\begin{array}{l}\text { Mj.max. } \\
\text { kond. }\end{array}$ & Počet. & Zavr. & Max. & $\begin{array}{l}\text { Na kraju } \\
\text { perioda }\end{array}$ \\
\hline \multirow{2}{*}{ I zona } & 0.58 & B & Dec. & Feb. & Mart & Apr. & 73 & 0 \\
\hline & 0.425 & $\mathrm{~B}$ & Dec. & Feb. & Mart & Maj & 160 & 0 \\
\hline \multirow{2}{*}{$\begin{array}{c}\text { I zona } \\
\text { Virpazar }\end{array}$} & 0.58 & $\mathrm{~B}$ & Dec. & Feb. & Mart & Maj & 107 & 0 \\
\hline & 0.58 & $\mathrm{~B}$ & Dec. & Feb. & Mart & Maj & 121 & 0 \\
\hline \multirow{2}{*}{ II zona } & 0.425 & $\mathrm{~B}$ & Nov. & Mart & April & Jul & 394 & 0 \\
\hline & 0.58 & B & Nov. & Mart & April & Jun & 236 & 0 \\
\hline \multirow{2}{*}{$\begin{array}{l}\text { II zona } \\
\text { Nikšić }\end{array}$} & 0.425 & B & Nov. & Mart & April & Avg. & 419 & 0 \\
\hline & 0.58 & B & Nov. & Mart & April & Jul & 258 & 0 \\
\hline \multirow{2}{*}{$\begin{array}{c}\text { II zona } \\
\text { Crkvice }^{+}\end{array}$} & 0.58 & B & Nov. & Mart & April & Jul & 299 & 0 \\
\hline & 0.58 & B & Nov. & April & Maj & Avg. & 321 & 0 \\
\hline \multirow{2}{*}{ III zona } & 0.425 & A & Nov. & Mart & April & Avg. & 409 & 0 \\
\hline & 0.425 & B & Okt. & April & Maj & Sept. & 662 & 293 \\
\hline \multirow{2}{*}{$\begin{array}{l}\text { III zona } \\
\text { Žabljak }\end{array}$} & 0.425 & A & Okt. & April & Maj & Sept. & 554 & 192 \\
\hline & 0.425 & B & Okt. & Maj & Jun & Sept. & 864 & 713 \\
\hline
\end{tabular}
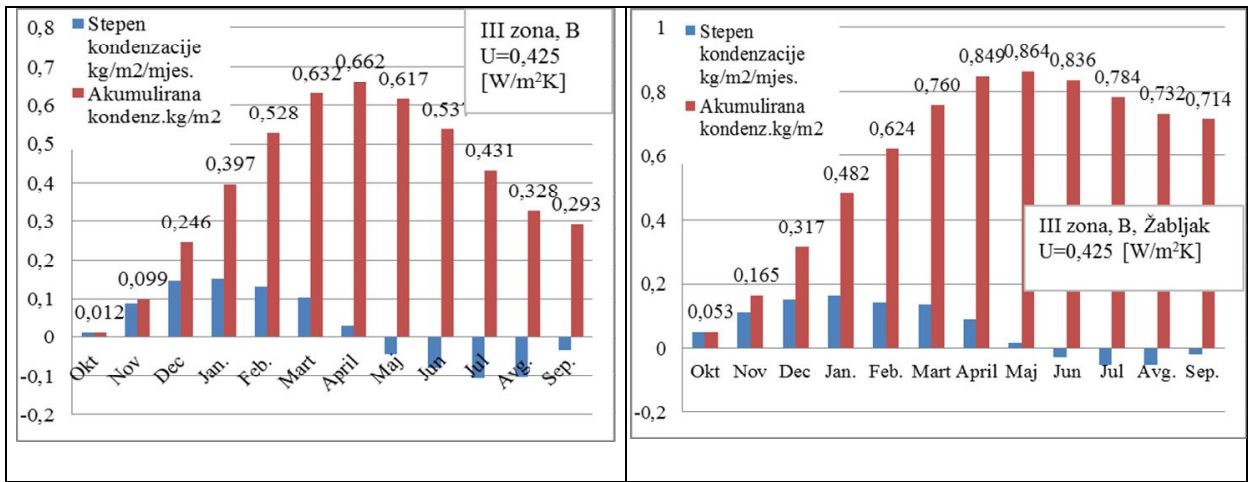

Slika 3. Stepen kondenzacije i isušenja za III zonu i prema prosječnim temperaturama za Žabljak, prema podacima ZHMS Crne Gore

\section{ZAKLJUČAK}

Razmatranje problema vlažnosti u zgradama predstavlja značajan aspekt realizovanja zdravih i trajnih zgrada. Ispunjenjem uslova minimalne termoizolovanosti ne obezbjeđuju se sigurni uslovi u pogledu vlažnosti. Objektivno predviđanje uslova za pojavu međuslojne kondenzacije u omotaču zgrade, i uslova za isušenje, su osnovni preduslovi za izbjegavanje štetnih posljedica dejstva vlage u konstrukcijama. Za određivanje parametara difuzije i međuslojne kondenzacije dominira upotreba Glaserove 
metode, bez obzira na značajna uprošćenja koja koristi. Ova metoda daje samo generalne podatke koji upućuju na postojanje problema. Međutim, vrlo gruba procjena klimatskih parametara može dati neadekvatne smjernice za njegovo postojanje.

Primjena tačnijih modela nije moguća bez definisanja adekvatnih klimatskih parametara, koji služe kao ulazni podaci za proračun. Potrebni su podaci o materijalu i klimatski podaci dovoljne tačnosti i obima za pokretanje ovog modela.

\title{
LITERATURA
}

[1] Benedetti, C., Demattio, M., Girasoli, M.T., Marchesi, M., Rondoni, M.: A new approach to energetic requalification of existing buildings: the impact of the planning decisions on moisture content and behaviour, World Sustainable Building Conference, Helsinki 2011.

[2] EN ISO 13788:2012, Hygrothermal performance of building components and building elements - Internal surface temperature to avoid critical surface humidity and interstitial condensation - Calculation methods.

[3] Tadeu, A., Simões, N., Branco, F.: Steady-state moisture diffusion in curved walls, in the absence of condensate flow, via the BEM: a practical Civil Engineering approach (Glaser Method). Building and Environment, 2003. Vol 38, pp. 677-688.

[4] Holm, A.: The influence of internal boundary conditions on the hygrothermal performance of construction assemblies, Institut Bauphysik.

[5] http://www.researchgate.net/publication/228529330_Assessment_Method_for_Com bined Heat Air and Moisture Transfer in Building Components, download 01.02 .2015 .

[6] Little, J.: Introducing hygrothermal building physics and WUFI simulations, Joseph Little Architects, 2011.

[7] Pravilnik o minimalnim zahtjevima energetske efikasnosti zgrada, Sl. list CG“, br. $23 / 2013$

\section{HYGROTHERMAL PERFORMANCE OF BUILDING IN RELATION TO THE CLIMATIC PARAMETERS}

\begin{abstract}
Summary: Transport of moisture through the elements of the cover can be analyzed using different methods, by adopting various climatic parameters, which can significantly influence reliability of results. This paper shows results of the calculations of interstitial condensation as a function of the adopted climatic elements. Glaser method is used for the calculation - despite being approximate it is still most widely recognized. It is concluded that the validity of calculations requires well defined national stipulations on climatic parameters.
\end{abstract}

Keywords: water vapour diffusion, interstitial condensation, climatic parameters 